\title{
Talanta
}

June 2017, Volume 168, Pages 298-302

\section{D-printed flow system for determination of lead in natural waters}

\author{
Mattio Elodie ${ }^{1}$, Robert-Peillard Fabien ${ }^{1}$, Branger Catherine ${ }^{2}$, Puzio Kinga ${ }^{2}$, Margaillan André ${ }^{2}$, \\ Brach-Papa Christophe ${ }^{3}$, Knoery Joël ${ }^{3}$, Boudenne Jean-Luc ${ }^{1}$, Coulomb Bruno ${ }^{1,{ }^{*}}$
}

\author{
${ }^{1}$ Aix Marseille Univ, CNRS, LCE, UMR 7376, Marseille, France \\ 2 University of Toulon, MAPIEM, La Garde, France \\ ${ }^{3}$ IFREMER, LBCM, Nantes, France \\ * Corresponding author : Bruno Coulomb, email address : bruno.coulomb@univ-amu.fr
}

\begin{abstract}
:
The development of 3D printing in recent years opens up a vast array of possibilities in the field of flow analysis. In the present study, a new 3D-printed flow system has been developed for the selective spectrophotometric determination of lead in natural waters. This system was composed of three 3Dprinted units (sample treatment, mixing coil and detection) that might have been assembled without any tubing to form a complete flow system. Lead was determined in a two-step procedure. A preconcentration of lead was first carried out on TrisKem $\mathrm{Pb}$ Resin located in a 3D-printed column reservoir closed by a tapped screw. This resin showed a high extraction selectivity for lead over many tested potential interfering metals. In a second step, lead was eluted by ammonium oxalate in presence of 4-(2-pyridylazo)-resorcinol (PAR), and spectrophotometrically detected at $520 \mathrm{~nm}$. The optimized flow system has exhibited a linear response from 3 to $120 \mu \mathrm{g}-1$. Detection limit, coefficient of variation and sampling rate were evaluated at $2.7 \mu \mathrm{g} \mathrm{L}-1,5.4 \%(n=6)$ and 4 sample $h-1$, respectively. This flow system stands out by its fully 3D design, portability and simplicity for low cost analysis of lead in natural waters.
\end{abstract}

\section{Graphical abstract}

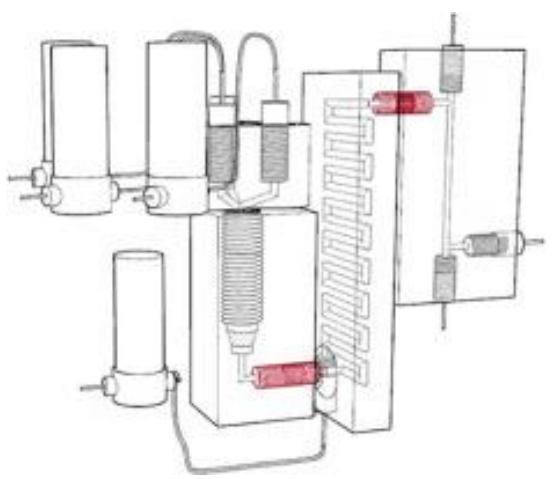




\section{Highlights}

A 3D-printed Multi Pumping Flow System is presented. Selective extraction of lead using Triskem $\mathrm{Pb}$ resin enables elimination of interferences. $\mathrm{Pb}^{2+}$ can be quantified between 3 and $120 \mu \mathrm{g} \mathrm{L}^{-1}$ with a LOD of $2.7 \mu \mathrm{g} \mathrm{L}^{-1}$. This flow system is a low cost and portable system allowing in-situ measurement.

Keywords : Lead determination ; 3D-printed MPFS system ; Stereolithography ; Natural waters 


\section{Introduction}

3 Lead is considered as one of the most toxic heavy metals [1] in the light of its environmental 4 [2] and health [3,4] impacts; it may cause irreversible neurological effects and digestive and kidney malfunctions. Its presence in the environment and more particularly in water can be mainly explained by anthropogenic sources like paints, arms and electronic [5] industries products. For these reasons, the World Health Organization has identified lead as one of the 10 chemicals of major public health concern [6] and has recommended a guideline value of 10 $\mu \mathrm{g} . \mathrm{L}^{-1}$ of lead in drinking water. It is therefore necessary to quantify lead by a rapid and efficient method to avoid toxic consumption.

Many methods are already available for lead determination such as spectrophotometry [7], voltammetry [8,9], graphic furnace atomic absorption spectrometry [10], or inductively coupled plasma spectroscopy [11,12], but they require costly and sophisticated devices and do not allow real-time and on-site measurements. In this context, mesofluidic and microfluidic systems can help to meet these needs thanks to their intrinsic advantages: miniaturization and low energy consumption, decreased reagents consumption and waste generation. Flow analysis offers many opportunities $[13,14]$ and Flow Injection Analysis (FIA), Sequential Injection Analysis (SIA) or MultiSyringe Flow Injection Analysis (MSFIA) based systems have been successfully applied for the determination of a wide range of substances in environmental matrices. Among flow analysis system, pulse flow systems using solenoid diaphragm micropumps (MPFS: Multi Pumping Flow System) present high flexibility, easy configuration and low cost. Another advantage is that the signal peaks are higher compared to other flow techniques, due to turbulences created by pump diaphragm strokes, which improve mixing between reagents and sample [15]. Recently, such MPFS systems were developed for phosphorous [16] or boron [17] determination in aqueous samples. 
Several units can be combined to create a flow system in full compliance with the analytical needs: solid phase extraction for pre-concentration, photo-oxidation or digestion, membrane or membrane-less separation, detection and many others. To increase versatility and ease of fabrication of flow systems, 3D printing is increasingly used in flow analysis $[18,19]$. This printing technology can be divided into three main categories: Fused Deposition Modeling (FDM) where a thermoplastic material is heated and extruded from a XYZ positionable nozzle, Multi Jet Modeling (MJM) which is based on an inkjet head to deposit liquid photopolymer (plastic resin or casting wax) layer by layer and finally stereolithography (SL) [20] invented in the 1980s and which is a layer manufacturing process with liquid materials [21] as MJM. SL is based on a mobile platform which dives in a resin tray, where a laser polymerizes the resin layer by layer. The most frequently used material is poly(methyl methacrylate) (PMMA) which allows to decrease fabrication cost and improve resolution [22]. 3D-printing technologies emergence enables creation of new type of units [23,24] for microfluidic systems which can be imagined and combined according to the analytical needs.

In this paper, the development of a novel 3D-printed multi-pumping flow system for the determination of lead in natural waters is presented. The system is composed of three 3Dprinted units: a resin column for lead solid phase extraction, a mixing coil and a classical flow cell for UV-Spectroscopy. The 3 modules are connected to one another by a screw system to limit tubings between the three units. Lead solid phase extraction is based on a commercial crown-ethers resin (TrisKem $\mathrm{Pb}$ resin) and the chromogenic reagent used for the spectrophotometric detection of lead is 4-(2-pyridylazo)resorcinol (PAR). The system was applied to the determination of lead in real river water samples.

\section{Materials and methods}

2.1.Reagents and samples 
1 All chemicals used were of analytical grade and used without further purification. Solutions

2 were prepared with ultra-pure water (Millipore, resistivity $>18 \mathrm{M} \Omega \mathrm{cm}$ ) and stocked in high density polyethylene flasks. Lead standard solutions were prepared by dilution of a commercial 1 g.L $\mathrm{L}^{-1}$ AAS lead stock solution (Fisher Chemical, USA) and stabilized with $1 \% \mathrm{v} / \mathrm{v}$ nitric acid trace metal grade (Fisher Chemical, USA). A multi-metal solution $\left(0.037 \mathrm{mmol} . \mathrm{L}^{-1}\right.$ for each metal) was prepared by dissolving appropriate amounts of lead nitrate and cadmium nitrate (Alfa Aesar, USA), nickel nitrate and copper nitrate (Merck, Germany), iron (III) sulphate and potassium chromate (VI) (Prolabo, France), cobalt nitrate, zinc nitrate, and aluminium chloride (Sigma-Aldrich, USA) in ultra-pure water.

The commercial TrisKem Pb Resin (PB-B25-S, 50-100 $\mu$ m, TrisKem, France) was used for lead extraction. The elution solution was prepared from ammonium oxalate (Prolabo, France). For detection, a $0.01 \mathrm{mmol} . \mathrm{L}^{-1}$ solution of 4-(pyridyl-2-azo)-resorcinol (PAR) monosodium salt (Merck, Germany) was prepared in a $1 \mathrm{mmol} \cdot \mathrm{L}^{-1}$ borate buffer solution $(\mathrm{pH}=12)$.

Freshwater samples were collected at purposely chosen points in a coastal river "The Arc" in the south-east of France, near industrial or urban effluents discharge points. All samples were UV-photo-oxidized with a $254 \mathrm{~nm}$ low-pressure mercury lamp (UVP PenRay, USA) during 30 minutes before analysis allowing liberation of lead linked to natural organic ligands, inorganic ligands or even to anthropogenic organic ligands.

\subsection{Apparatus}

\subsubsection{Flow system}

The three units of the MPFS system (Fig. 1) were designed with Rhinoceros® 5.0 3D software (Robert McNeel \& Associates Europe, Spain), then printed with a poly(methyl methacrylate) resin on the 3D printer Form1+ (Formlabs, USA). The first unit consisted of a resin column, tightly closed by a screw piece with three entry channels for injection of sample and reagents. 
1 The resin was packed in this unit between two layers of glass wool. To optimize mixing of

2 eluate and chromogenic reagent used for lead detection (PAR), a second unit composed of a serpentine mixing coil ( $1.5 \mathrm{~mm}$ internal diameter, $50 \mathrm{~cm}$ length) and of a connection for PAR inlet was added to the system. Finally, the detection step was performed with a classical spectroscopic flow-cell with a 5-cm optical pathlength. Sample and reagents were introduced inside the system by means of four solenoid micro-pumps (Bio-ChemValve Inc., USA) that had a stroke volume of $20 \mu \mathrm{L}$ and a high frequency of 250 cycles/min. These pumps were computercontrolled by a MCFIA/MPFS system (Sciware, Spain) with eight digital 12V output channels. For the detection, two FC-UV600 optical fibres (Ocean Optics, USA) were connected at the ends of the optical pathlength, and isolated from the reaction mixture with two tailor-made quartz discs, to guide the light from the source to the spectrophotometric detector. The radiation of the halogen bulb of a DH-2000 UV-Vis light source (Ocean Optics, USA) was transmitted to a USB2000 miniature spectrometer detector (Ocean Optics, USA). The whole system was controlled by AutoAnalysis 5.0 software (Sciware, Spain).

\subsubsection{Metal analysis}

Graphite furnace atomic absorption spectrometry (GF-AAS) was used to optimize the extraction/elution steps on TrisKem $\mathrm{Pb}$ resin and validate lead amounts in real samples (after filtration on a $0.45 \mu \mathrm{m}$ polyethersulfone membrane). The measurements were carried out on a Thermo Scientific ICE3500 (USA) atomic absorption spectrometer equipped with a lead hollow-cathode lamp operated at $10 \mathrm{~mA}$ (wavelength of $217 \mathrm{~nm}$ ). Argon flow was 0.2 L.min ${ }^{-1}$ except during atomisation step (no flow). The furnace settings were: drying at $110{ }^{\circ} \mathrm{C}$, ramp for $9 \mathrm{~s}$, hold for $35 \mathrm{~s}$; cracking at $800{ }^{\circ} \mathrm{C}$, ramp for $5 \mathrm{~s}$, hold for $20 \mathrm{~s}$; atomising at $1200{ }^{\circ} \mathrm{C}$, ramp for $1 \mathrm{~s}$ and $3 \mathrm{~s}$ hold; cleaning at $2500{ }^{\circ} \mathrm{C}$, no ramp and $3 \mathrm{~s}$ hold. 
1 Interfering cations were determined by inductively coupled plasma-atomic emission

8 spectrometry (ICP-AES) with a Jobin YVON JY2000 Ultratrace spectrometer, equipped with a CMA spray chamber and a Meinhard R50-C1 glass nebuliser. Determinations were performed with the following settings: power $1000 \mathrm{~W}$, pump speed $20 \mathrm{~mL} \cdot \mathrm{min}^{-1}$, plasma flow rate 12 L.min ${ }^{-1}$, coating gas flow rate $0.2 \mathrm{~L} . \mathrm{min}^{-1}$, nebuliser flow rate $0.9 \mathrm{~L} . \mathrm{min}^{-1}$ and nebuliser pressure 2.08 bar.

\subsection{Flow procedure}

The MPFS system was operated according to the procedure in 6 steps given in Table 1: in step $1,9 \mathrm{~mL}$ of nitric acid solution $\left(0.05 \mathrm{~mol} . \mathrm{L}^{-1}\right)$ was used for conditioning the $\mathrm{Pb}$ resin and washing the system before analysis. Then $50 \mathrm{~mL}$ of acidified sample were introduced in the system (step 2). In step 3, the resin was washed again with nitric acid solution $\left(0.05 \mathrm{~mol}^{-\mathrm{L}^{-1}}\right)$ to eliminate potential interfering species extracted by the resin. $5 \mathrm{~mL}$ of ammonium oxalate solution $(0.025$ mol. $\left.\mathrm{L}^{-1}\right)$ and PAR $\left(0.01 \mathrm{mmol} . \mathrm{L}^{-1}\right)$ were simultaneously pumped through the resin to eluate extracted lead and at the inlet of the mixing coil, respectively (steps 4-5).

Measurements were based on the peak height. The analytical signal was recorded at $520 \mathrm{~nm}$ when the elution started. Absorbance spectra were acquired every $0.5 \mathrm{~s}$, with an integration time of $55 \mathrm{~ms}$ and an average of 3 spectra.

\section{Results and discussion}

3.1.Extraction and washing steps

\subsubsection{Influence of concentration of nitric acid}

The developed system was based on the spectrophotometric determination of lead in the presence of PAR reagent. However, it is well known that lead determination by this simple method often suffers from interferences of cadmium, copper and zinc [25]. Therefore, the 
concentration of these interfering metals should be reduced before PAR detection to allow selective determination of lead.

Lead determination was thus based on extraction properties of the resin TrisKem $\mathrm{Pb}$ resin. This resin was initially developed for the separation of ${ }^{210} \mathrm{~Pb}$ and ${ }^{210} \mathrm{Po}$ and is constituted by crownethers diluted in isodecanol and impregnated on an inert support. The length of the carbon chain of isodecanol facilitates lead elution. Its retention capacity is $29 \mathrm{mg} \mathrm{Pb} / \mathrm{g}$ of resin. The manufacturer's instructions recommend acidification of samples with 1 mol.L $\mathrm{L}^{-1}$ nitric acid before extraction of lead on TrisKem $\mathrm{Pb}$ resin. However, the first experiments carried out with 1 mol.L $L^{-1}$ nitric acid led, after a few injections, to yellowing and cracking of the inlet of 3Dprinted column part. The effect of $\mathrm{HNO}_{3}$ concentration on the extraction of lead and potentially interfering metals was thus tested in the range $0-0.1$ mol. $\mathrm{L}^{-1}$ in order to preserve $3 \mathrm{D}$-printed parts.

The results in Fig. 2 showed that more than $90 \%$ of lead was extracted with $\mathrm{HNO}_{3}$ concentration above 0.02 mol. $\mathrm{L}^{-1}$. The best lead extraction (97\%) was obtained with $\mathrm{HNO}_{3} 0.1$ mol.L $\mathrm{L}^{-1}$.

Concerning the other metal cations, iron was also partially extracted (20-50\%, with the highest extraction at $\left.0.1 \mathrm{~mol} \cdot \mathrm{L}^{-1}\right)$. Aluminium, copper and zinc were not retained by the resin whatever the acid concentration. For $\mathrm{HNO}_{3}$ concentrations of 0.02 and 0.05 mol. $\mathrm{L}^{-1}$, a very few amount $(\leq 5 \%)$ of cobalt, chromium, and cadmium was extracted. It can therefore be concluded that the resin has an excellent selectivity for lead over other metals, except for iron for which extraction is dependent on $\mathrm{HNO}_{3}$ concentration. A nitric acid concentration of $0.05 \mathrm{~mol} . \mathrm{L}^{-1}$ appeared to be sufficient to extract lead quantitatively and to limit the extraction rate of iron below $20 \%$. After metal extraction on the resin, a washing step can improve the selectivity by removing potentially interfering metals without eluting the analyte of interest. This washing step has also been studied with different $\mathrm{HNO}_{3}$ concentrations. Based on the previous results, only iron and lead were studied. The washing solutions were collected and analysed by ICP-AES. As can be 
seen in Fig. 3 the amount of both iron and lead washed out decreased with increasing $\mathrm{HNO}_{3}$ concentration. With $\mathrm{HNO}_{3} 0.02$ mol. $\mathrm{L}^{-1}$, all the iron retained within the resin was eliminated, but an important lead elution rate of $42 \%$ was also observed. A nitric acid concentration of 0.05 mol. $\mathrm{L}^{-1}$ seems to be the best compromise between iron elimination $(75 \%)$ and limited lead elution rate (about $10 \%)$.

To summarize 0.05 mol. $\mathrm{L}^{-1} \mathrm{HNO}_{3}$ may be used for both extraction and washing steps, thereby limiting the number of pumps to be used in the system.

Sample flow rate was studied from 2 to $5 \mathrm{~mL} \cdot \mathrm{min}^{-1}$ for a sample volume of $30 \mathrm{~mL}$. Samples were acidified with 0.05 mol.L $\mathrm{L}^{-1} \mathrm{HNO}_{3}$ before extraction. As displayed in supplementary material (Fig. S1), results showed an important increase of lead extraction from $3 \mathrm{~mL} \cdot \mathrm{min}^{-1}$ to $5 \mathrm{~mL} \cdot \mathrm{min}^{-1}$. At the highest flow rate $\left(5 \mathrm{~mL} \cdot \mathrm{min}^{-1}\right)$ the extraction percentage of lead reached 94 $\%$.

To avoid overpressure problem of solenoid pumps or clogging of resin column, the column inner diameter and height has been set respectively at $7.8 \mathrm{~mm}$ and $4.5 \mathrm{~mm}$, which are higher than in a traditional packed column. None of the previously mentioned problems were observed during analysis. Although solenoid pumps are not usually suitable for resin solid phase extraction, it seems that high sample flow rates enable fluidizing of the resin bed and thus good lead extraction. Therefore, a $5 \mathrm{~mL} \cdot \mathrm{min}^{-1}$ flow rate was chosen for the system.

\subsection{Elution step}

Ammonium oxalate is recommended by the resin manufacturer for lead elution. The lead elution has thus been studied at different concentrations of ammonium oxalate. The elution flow rate has been adjusted at $4 \mathrm{~mL} \cdot \mathrm{min}^{-1}$, according to the resin manufacturer instructions. 
1 The results shown in Fig. 4 highlighted that elution efficiency increased with ammonium

2 oxalate concentration up to 0.05 mol.L $\mathrm{L}^{-1}$.

3 For concentration of ammonium oxalate between 0.025 and $0.1 \mathrm{~mol} . \mathrm{L}^{-1}$, the results obtained were not significantly different. To limit reagent consumption, the concentration of ammonium oxalate was adjusted at $0.025 \mathrm{~mol} . \mathrm{L}^{-1}$ for further experiments.

\subsection{Detection}

Lead elution profile has been studied by collecting small fractions $(0.5 \mathrm{~mL})$ of ammonium oxalate used for elution with a flow rate of $5 \mathrm{~mL} \cdot \mathrm{min}^{-1}$. As can be seen on Fig.S2 (Supplementary material), elution was complete within one minute (elution rate of $99 \%$ of total extracted lead after $5 \mathrm{~mL}$ ).

Lead was detected by spectrophotometry using a PAR solution pumped simultaneously and mixed with ammonium oxalate in the mixing coil. PAR solution was buffered with borate solution at $\mathrm{pH}=12$ in order to obtain a mixture at $\mathrm{pH}=9$ (optimised for $\mathrm{UV}-\mathrm{Vis}$ detection) when mixed with ammonium oxalate which $\mathrm{pH}$ is around 6.6.

PAR reagent and ammonium oxalate flow rates were studied from 1 to $5 \mathrm{~mL} \cdot \mathrm{min}^{-1}$. Optimization was carried out with a standard lead solution of $100 \mu \mathrm{g} . \mathrm{L}^{-1}$. PAR flow rate was optimized using a fixed ammonium oxalate flow rate of $5 \mathrm{~mL} \cdot \mathrm{min}^{-1}$ and inversely. Fig. 5 showed that the best absorbance was obtained with the maximum flow rate of the pumps useable for the two reagents $\left(5 \mathrm{~mL} \cdot \mathrm{min}^{-1}\right)$. The absorbance increased regularly with increasing PAR flow rate. The absorbance values increased slightly with an ammonium oxalate flow rate between 1 and $4 \mathrm{~mL} \cdot \mathrm{min}^{-1}$ and, strongly increased for a flow rate of $5 \mathrm{~mL} \cdot \mathrm{min}^{-1}$. This observation was consistent with results obtained for sample flow rate with better efficiency at high flow rates. However, eluent flow rate seemed to have less influence than sample flow rate. Flow rates of PAR and ammonium oxalate were thus fixed at $5 \mathrm{~mL} \cdot \mathrm{min}^{-1}$. 
3 Calibration curves have been constructed for various sample volumes (10, 25 and $50 \mathrm{~mL})$. From these data, limits of detection (LOD; $3 \sigma ; n=10)$ and coefficient of variation $(\mathrm{CV} ; \mathrm{n}=6)$ were determined and summarized in Table S1 (Supplementary material). The analytical features obtained for a $50 \mathrm{~mL}$ sample volume seemed adapted for typical lead concentrations in natural waters: LOD was calculated at $2.7 \mu \mathrm{g} . \mathrm{L}^{-1}$, linear domain range was between 3 and $120 \mu \mathrm{g} . \mathrm{L}^{-1}$. The LOD was acceptable for environmental sample analysis, but sample volume can potentially be increased if lower LOD needs to be reached for water samples with very small amounts of lead. An additional experiment has been carried out and a volume of $200 \mathrm{~mL}$ of sample has been passed through the TrisKem $\mathrm{Pb}$ resin column. The results obtained showed that no traces of lead were detected at the column outlet and that the breakthrough volume of the resin was not reached. Coefficient of variation obtained with the optimal conditions $(50 \mathrm{~mL}$ sample volume), for a lead concentration of $50 \mu \mathrm{g} . \mathrm{L}^{-1}$ was $5.4 \%$.

A brief comparison of previously reported flow methods for lead determination with proposed 3D-printed flow system is given in Table 2. Some of these methods require complicated or expensive equipment in particular for detection step [26,27,29,30]. Compared to other simpler flow procedures using spectrophotometric detection [28,31], the proposed method has a lower detection limit better suited for analysis of natural water samples.

\subsection{Validation}

In order to validate the 3D-printed optimized system, five samples of freshwater have been collected at purposely chosen points in a coastal river ("The Arc", south of France) in areas close to anthropogenic activities. The samples were UV-photooxidized at $254 \mathrm{~nm}$ during 30 minutes and filtered at $0.45 \mu \mathrm{m}$ before analysis. These samples have been analyzed in duplicate 
1 by ICP-AES and developed 3D-printed system with a sample volume of $50 \mathrm{~mL}$, and the results

2 were summarized in Table 3.

3 The values obtained by the two methods were consistent. The mean difference between the two

4 methods was $5.8 \%$, $(\min -11.2 \%$; $\max 11.7 \%)$. The results obtained by the proposed system

5 were compared ( $t$ test) with the reference method values (ICP-AES) and no significant

6 differences at the $95 \%$ confidence level were found.

7

\section{Conclusion}

A 3D-printed system was developed for determination of lead in natural waters. Lead quantification was based on the selective solid phase extraction of lead on TrisKem $\mathrm{Pb}$ resin followed by elution with ammonium oxalate and spectrophotometric detection using 4-(2pyridylazo)-resorcinol as chromophoric reagent. Interferences were eliminated by optimisation of extracting and washing steps on TrisKem Pb resin. Detection limit obtained $\left(2.7 \mu \mathrm{g} . \mathrm{L}^{-1}\right)$ was consistent with environmental samples analysis but sample volume may be increased if lower detection limits are needed. The proposed flow system was compared to a reference method (ICP-AES) and was satisfactorily applied to natural waters samples. The optimized 3D-printed MPFS flow system could be controlled by an open-source microcontroller board to design a low cost portable on-line analyzer $[16,17]$.

\section{Acknowledgment}

This work was included in the project "Lab-on-Ship" funded by the French Research Agency (ANR-14-CE04-0004).

\section{References}


1 [1] R. Garnier, Toxicité du plomb et de ses dérivés, EMC - Toxicologie-Pathologie. 2 (2005)

$2 \quad 67-88$.

3 [2] M. Dikilitas, S. Karakas, P. Ahmad, Chapter 3 - Effect of Lead on Plant and Human DNA

4 Damages and Its Impact on the Environment, in: Plant Metal Interaction, Elsevier, 2016: pp.

$5 \quad 41-67$.

6 [3] D.R. Juberg, Lead and human health: An update, Am Cncl on Science, Health, 2000.

7

[4] F.M. Johnson, The genetic effects of environmental lead, Mutation Research 410 (1998)

$8 \quad 123-140$.

[5] M. Pecht, Y. Fukuda, S. Rajagopal, The impact of lead-free legislation exemptions on the electronics industry, IEEE Transactions on Electronics Packaging Manufacturing 27 (2004) $221-232$.

[6] World Health Organization | Lead poisoning and health, WHO. http://www.who.int/mediacentre/factsheets/fs379/en/ (accessed November 10, 2016). [7] I. Rahman, Y. Furusho, Z. Begum, R. Sato, H. Okumura, H. Honda, H. Hasegawa, Determination of lead in solution by solid phase extraction, elution, and spectrophotometric detection using 4-(2-pyridylazo)-resorcinol, Central European Journal of Chemistry 11 (2013) 672-678.

[8] H. Fang, F. Tang, J. Shi, H. Zheng, L. Bi, W. Wang, Determination of trace lead and cadmium using stripping voltammetry in fluidic microchip integrated with screen-printed carbon electrodes, Instrumentation Science \& Technology 40 (2012) 590-602.

[9] G. Abate, J.C. Masini, Complexation of Cd (II) and Pb (II) with humic acids studied by anodic stripping voltammetry using differential equilibrium functions and discrete site models, Organic Geochemistry 33 (2002) 1171-1182. 
$1 \quad[10]$ K.W. Bruland, K.H. Coale, L. Mart, Analysis of seawater for dissolved cadmium, copper

2 and lead: An intercomparison of voltammetric and atomic absorption methods, Marine

3 Chemistry 17 (1985) 285-300.

4 [11] T.-Y. Ho, C.-T. Chien, B.-N. Wang, A. Siriraks, Determination of trace metals in

5 seawater by an automated flow injection ion chromatograph pretreatment system with

$6 \quad$ ICPMS, Talanta $82(2010)$ 1478-1484.

7 [12] M. Zougagh, A. García de Torres, E. Vereda Alonso, J.M. Cano Pavón, Automatic on

8 line preconcentration and determination of lead in water by ICP-AES using a TS-

9 microcolumn, Talanta 62 (2004) 503-510.

[13] V. Cerdà, J.M. Estela, R. Forteza, A. Cladera, E. Becerra, P. Altimira, P. Sitjar, Flow techniques in water analysis, Talanta 50 (1999) 695-705.

[14] M. Trojanowicz, Advances in Flow Analysis, John Wiley \& Sons, 2008.

[15] J.L.M. Santos, M.F.T. Ribeiro, A.C.B. Dias, J.L.F.C. Lima, E.E.A. Zagatto, Multipumping flow systems: The potential of simplicity, Analytica Chimica Acta 600 (2007) 2128.

[16] P. González, N. Pérez, M. Knochen, P. González, N. Pérez, M. Knochen, Low cost analyzer for the determination of phosphorus based on open-source hardware and pulsed flows, Química Nova 39 (2016) 305-309.

[17] P. González, A. Sixto, M. Knochen, Multi-pumping flow system for the determination of boron in eye drops, drinking water and ocean water, Talanta 166 (2017) 399-404.

[18] N. Bhattacharjee, A. Urrios, S. Kang, A. Folch, The upcoming 3D-printing revolution in microfluidics, Lab on a Chip 16 (2016) 1720-1742.

[19] A.K. Au, W. Huynh, L.F. Horowitz, A. Folch, 3D-Printed Microfluidics, Angewandte Chemie International Edition 55 (2016) 3862-3881. 
1 [20] A.K. Au, W. Lee, A. Folch, Mail-order microfluidics: evaluation of stereolithography

2 for the production of microfluidic devices, Lab on a Chip 14 (2014) 1294-1301.

3 [21] P.J. Bártolo, Stereolithography: Materials, Processes and Applications, Springer

4 Science \& Business Media, New York, 2011.

5 [22] C. Polzin, S. Spath, H. Seitz, Characterization and evaluation of a PMMA-based 3D

6 printing process, Rapid Prototyping Journal 19 (2013) 37-43.

7 [23] R.M. Frizzarin, E. Aguado, L.A. Portugal, D. Moreno, J.M. Estela, F.R.P. Rocha, V.

8 Cerdà, A portable multi-syringe flow system for spectrofluorimetric determination of iodide in seawater, Talanta 144 (2015) 1155-1162.

[24] V. Cerdà, J. Avivar, D. Moreno, Chips: How to build and implement fluidic devices in flow based systems, Talanta, 166 (2017) 412-419.

[25] R.M. Dagnall, T.S. West, P. Young, Determination of lead with 4-(2-pyridylazo)resorcinol, Talanta 12 (1965) 583-588.

[26] C. Mitani, A.N. Anthemidis, On-line liquid phase micro-extraction based on drop-in-plug sequential injection lab-at-valve platform for metal determination, Analytica Chimica Acta 771 (2013) 50-55.

[27] B. Beltran, L. O. Leal, L. Ferrer, V. Cerda, Determination of lead by atomic fluorescence spectrometry using an automated extraction/pre-concentration flow system, Journal of Analytical Atomic Spectrometry 30 (2015) 1072-1079.

[28] M. S. Di Nezio, M. E. Palomeque, B. S. Fernandez Band, A sensitive spectrophotometric method for lead determination by flow injection analysis with on-line preconcentration, Talanta 63 (2004) 405-409.

[29] A. N. Anthemidis, K.-I. G. Ioannou, On-line sequential injection dispersive liquid-liquid microextraction system for flame atomic absorption spectrometric determination of copper and lead in water samples, Talanta 79 (2009) 86-91. 
1 [30] P. Ampan, J. Ruzicka, R. Atallah, G.D. Christian, J. Jakmunee, K. Grudpan, Exploiting

2 sequential injection analysis with bead injection and lab-onvalve for determination of lead using

3 electrothermal atomic absorption spectrometry, Analytica Chimica Acta 499 (2003) 167-172.

4 [31] R.B.R. Mesquita, S.M.V. Fernandes, A.O.S.S. Rangel, A flow system for the 5 spectrophotometric determination of lead in different types of waters using ion-exchange for 6 pre-concentration and elimination of interferences, Talanta 62 (2004) 395-401.

7

8 


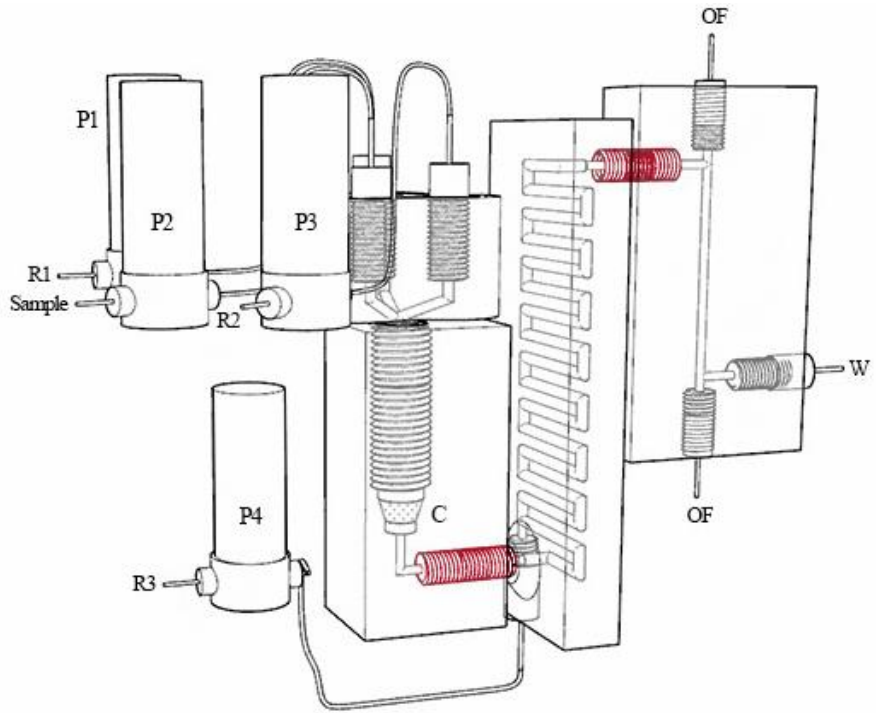

2 Fig. 1. Schema of the MPFS system with the three 3D printed units. C: resin column, R1: nitric

3 acid, R2: ammonium oxalate, R3: PAR, OF: optical fiber, W: waste. In red, the screws and 4 corresponding screw threads to assemble the units.

5 


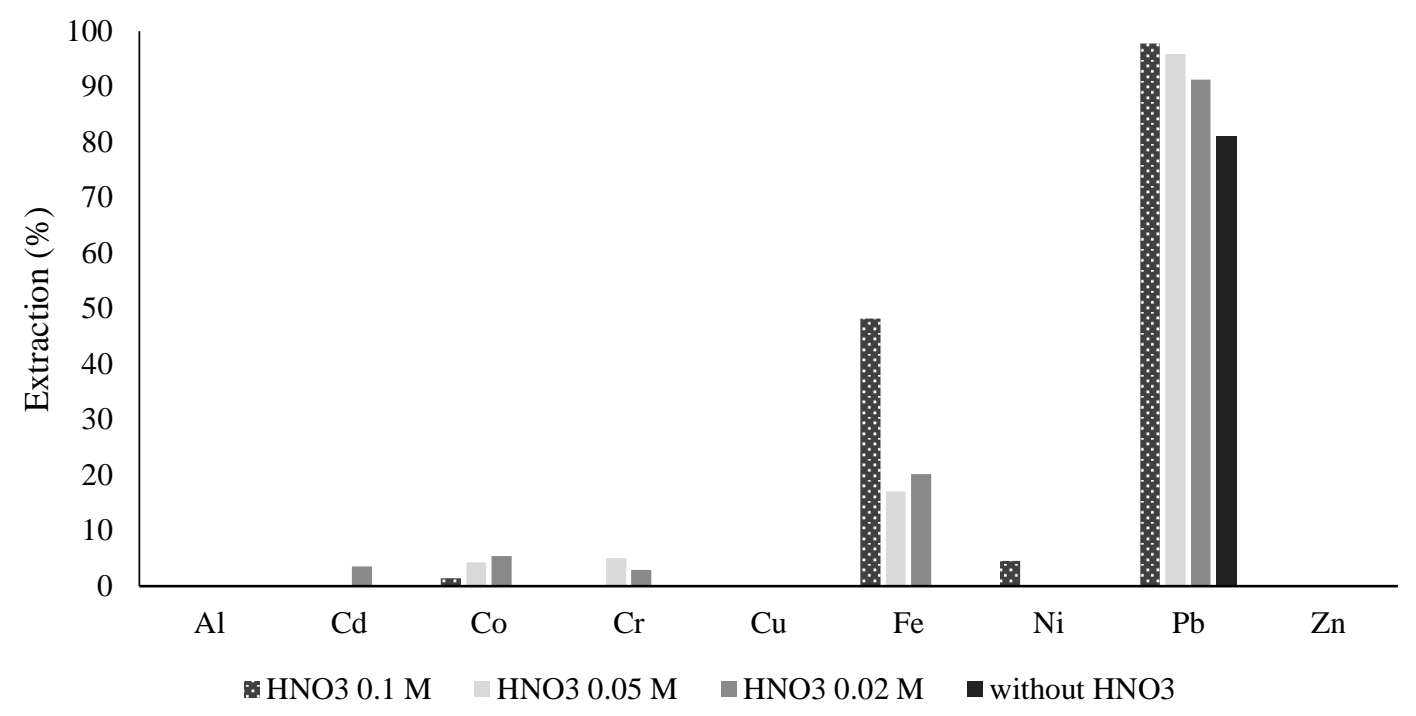

2 Fig. 2. Extraction of several metals on TrisKem $\mathrm{Pb}$ resin for different concentrations of nitric

3 acid [multi-metal solution at $0.037 \mathrm{mmol} . \mathrm{L}^{-1}\left(\mathrm{~V}=30 \mathrm{~mL}\right.$ at $\left.3 \mathrm{~mL} \cdot \mathrm{min}^{-1}\right)$, nitric acid at $5 \mathrm{~mL} \cdot \mathrm{min}^{-}$

$4{ }^{1}\left(\mathrm{~V}=9 \mathrm{~mL}\right.$ for conditioning step, $\mathrm{V}=6 \mathrm{~mL}$ for washing step), ammonium oxalate at $0.1 \mathrm{~mol} . \mathrm{L}^{-}$

$5 \quad{ }^{1}\left(\mathrm{~V}=10 \mathrm{~mL}\right.$ at $\left.\left.4 \mathrm{~mL} \cdot \mathrm{min}^{-1}\right)\right]$.

6 


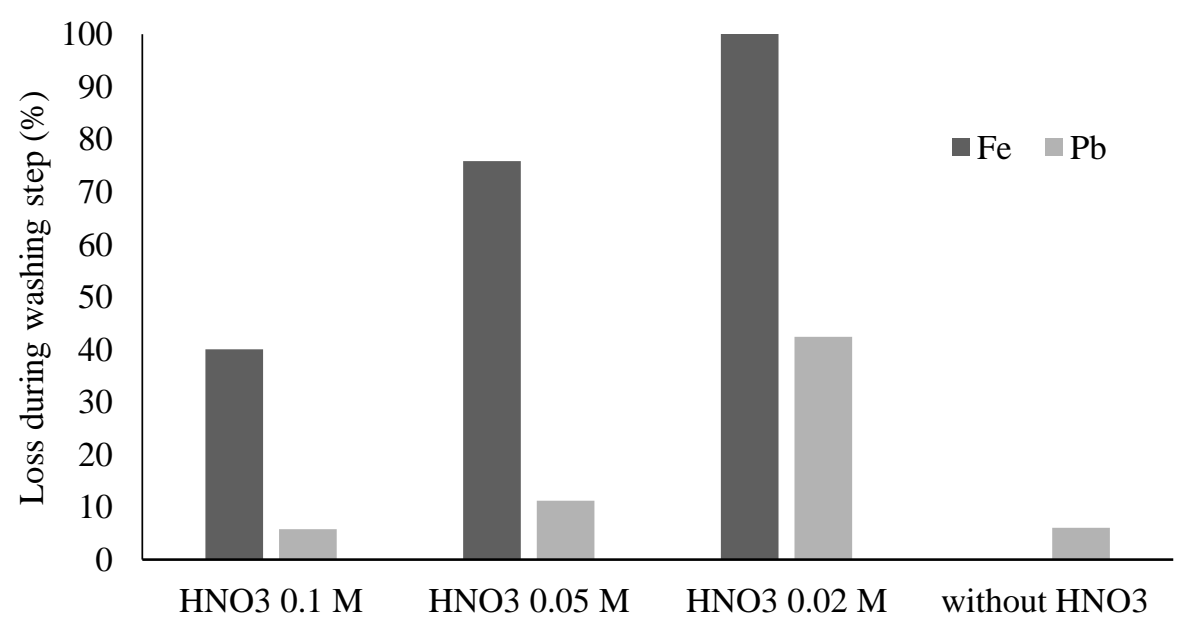

1

2 Fig. 3. Iron and lead washing out during washing step [multi-metal solution at $0.037 \mathrm{mmol} . \mathrm{L}^{-1}$

$3 \quad(\mathrm{~V}=30 \mathrm{~mL}$ at $3 \mathrm{~mL} \cdot \mathrm{min}-1)$, nitric acid at $5 \mathrm{~mL} \cdot \mathrm{min}^{-1}(\mathrm{~V}=9 \mathrm{~mL}$ for conditioning step, $\mathrm{V}=6$

$4 \mathrm{~mL}$ for washing step), ammonium oxalate at $0.1 \mathrm{~mol} \cdot \mathrm{L}^{-1}\left(\mathrm{~V}=10 \mathrm{~mL}\right.$ at $\left.4 \mathrm{~mL} \cdot \mathrm{min}^{-1}\right)$.

5 


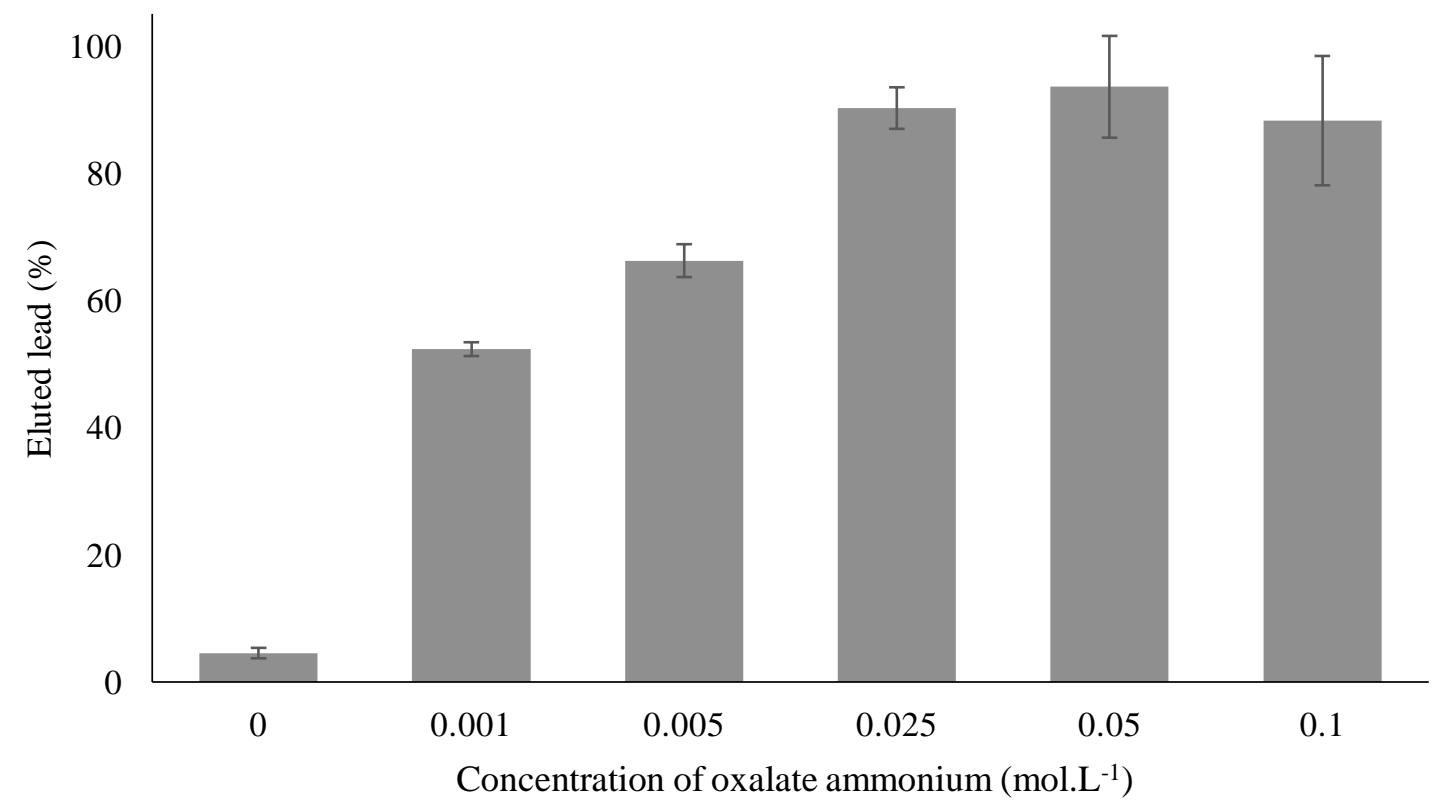

1

2 Fig. 4. Elution of lead at different concentrations of ammonium oxalate [lead solution at 100

$3 \mu \mathrm{g} . \mathrm{L}^{-1}\left(\mathrm{~V}=30 \mathrm{~mL}\right.$ at $\left.5 \mathrm{~mL} \cdot \mathrm{min}^{-1}\right)$, nitric acid at $0.05 \mathrm{~mol} \cdot \mathrm{L}^{-1}(\mathrm{~V}=9 \mathrm{~mL}$ for conditioning step,

$4 \mathrm{~V}=6 \mathrm{~mL}$ for washing step, at $\left.5 \mathrm{~mL} \cdot \mathrm{min}^{-1}\right)$, ammonium oxalate at $\left.4 \mathrm{~mL} \cdot \mathrm{min}^{-1}(\mathrm{~V}=10 \mathrm{~mL})\right]$. 5 


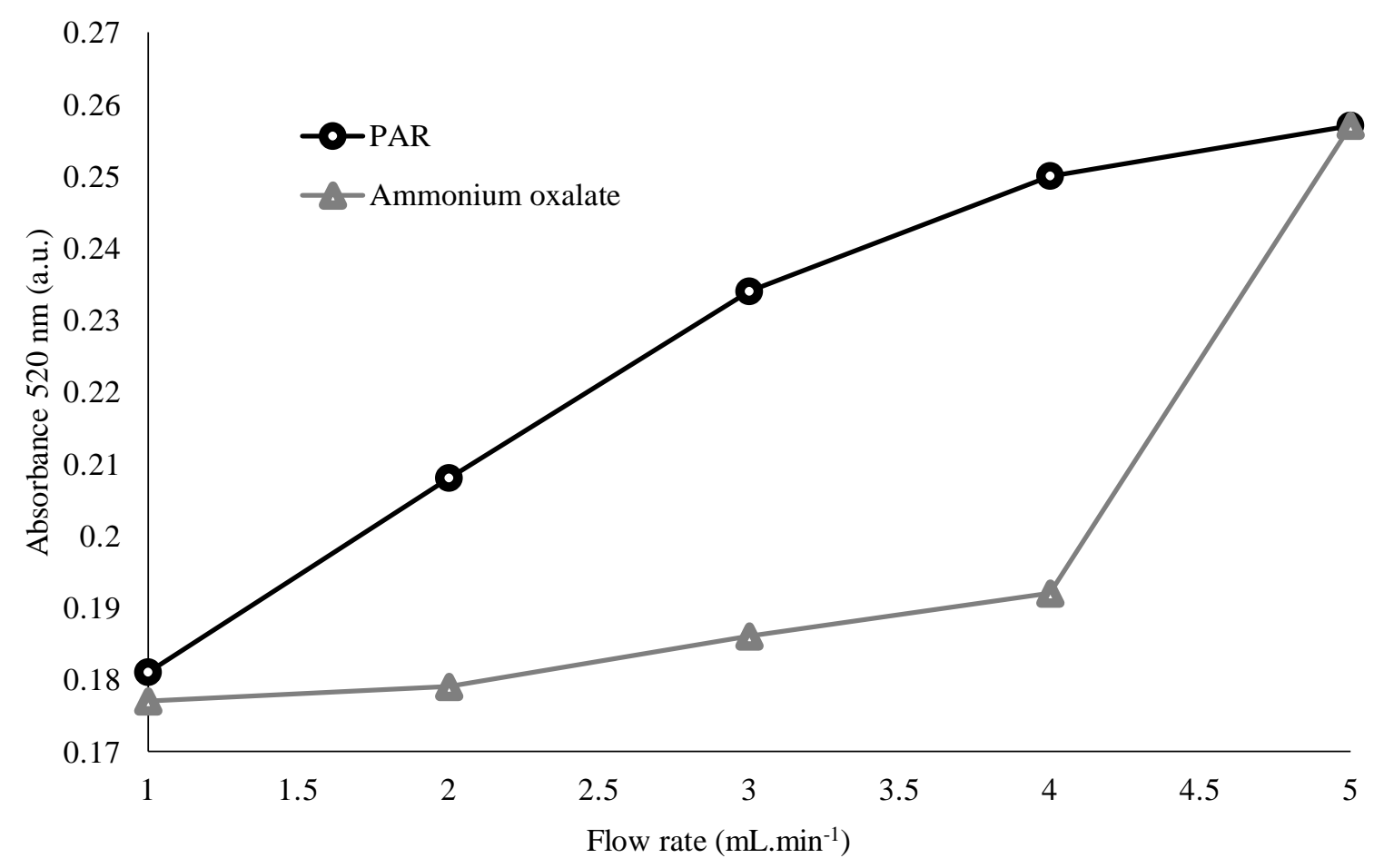

1

Fig. 5. Absorbance versus PAR and ammonium oxalate flow rates [lead solution at $100 \mu \mathrm{g} . \mathrm{L}^{-1}$

$3 \quad\left(\mathrm{~V}=30 \mathrm{~mL}\right.$ at $\left.5 \mathrm{~mL} \cdot \mathrm{min}^{-1}\right)$, nitric acid at $0.05 \mathrm{~mol} \cdot \mathrm{L}^{-1}(\mathrm{~V}=9 \mathrm{~mL}$ for conditioning step, $\mathrm{V}=6$

$4 \mathrm{~mL}$ for washing step, at $\left.5 \mathrm{~mL} \cdot \mathrm{min}^{-1}\right)$, ammonium oxalate at $0.025 \mathrm{~mol} \cdot \mathrm{L}^{-1}(\mathrm{~V}=10 \mathrm{~mL}), \mathrm{PAR}$

5 at $\left.0.01 \mathrm{mmol} \cdot \mathrm{L}^{-1}(\mathrm{~V}=10 \mathrm{~mL})\right]$.

6 
1 Table 1 Flow procedure for lead determination in water

\begin{tabular}{lllcccccc}
\hline Step & \multicolumn{1}{c}{ Description } & Action & $\begin{array}{c}\text { Volume } \\
(\mathbf{m L})\end{array}$ & $\begin{array}{c}\text { Flow-rate } \\
\left(\mathbf{m L} \cdot \mathbf{m i n}^{-1}\right)\end{array}$ & P1 & P2 & P3 & P4 \\
\hline 1 & Conditioning & Pumping nitric acid & 9 & 5 & ON & OFF & OFF & OFF \\
2 & Pb extraction & Pumping sample & 50 & 5 & OFF & ON & OFF & OFF \\
3 & Washing & Pumping nitric acid & 6 & 5 & ON & OFF & OFF & OFF \\
4 & Start data acquisition & - & - & - & & & & \\
5 & Elution \& detection & $\begin{array}{l}\text { Pumping ammonium } \\
\text { oxalate and PAR }\end{array}$ & 5 & 4 & OFF & OFF & ON & ON \\
6 & Stop data acquisition & - & - & - & & & & \\
\hline
\end{tabular}


1 Table 2 Comparison of flow methods for lead determination in water samples.

2

\begin{tabular}{|c|c|c|c|c|c|c|}
\hline Reference & $\begin{array}{c}\text { Flow } \\
\text { technique }\end{array}$ & $\begin{array}{l}\text { Preconcentration } \\
\text { mode }^{\mathrm{b}}\end{array}$ & $\begin{array}{l}\text { Detection } \\
\text { system }^{c}\end{array}$ & $\begin{array}{c}\text { Linear range } \\
\left(\mu \mathrm{g} . \mathrm{L}^{-1}\right)\end{array}$ & $\begin{array}{l}\text { Precision } \\
\text { (\%) }\end{array}$ & LOD $(\mu \mathrm{g} . \mathrm{L}$ \\
\hline [26] & SI-LAV & LPME & FAAS & $6-300$ & 2.9 & 1.8 \\
\hline [27] & LOV & SPE & HG-AFS & $0.014-20$ & 2.4 & 0.004 \\
\hline [28] & FIA & SPE & Vis & $25-250$ & 4.5 & 5 \\
\hline [29] & SI & DLLME & FAAS & $2.3-160$ & 1.9 & 0.54 \\
\hline [30] & SI-LOV & BI & ETAAS & $2-8$ & 1.9 & 0.6 \\
\hline [31] & SI & SPE & Vis & $50-300$ & 4 & 25 \\
\hline $\begin{array}{l}\text { Present } \\
\text { work }\end{array}$ & MPFS & SPE & Vis & $3-120$ & 5.4 & 2.7 \\
\hline
\end{tabular}

${ }^{\text {a }}$ MPFS: multipumping flow system; SI-LAV: sequential injection - lab-at-valve; LOV: labon-valve; FIA: flow injection analysis; SI : sequential injection; SI-LOV: sequential injection - lab-on-valve

${ }^{\mathrm{b}}$ LPME : liquid phase micro-extraction; SPE : solid phase extraction ; DLLME: dispersive liquid-liquid micro-extraction; BI: bead injection

${ }^{c}$ FAAS: flame atomic absorption spectrometry; Vis: visible spectrophotometry; HG-AFS: hydride generation-atomic fluorescence spectroscopy; ETAAS: electrothermal atomic absorption spectrometry 
1 Table 3 Lead determination in real natural water samples with optimised 3D-printed flow

2 system vs reference method (ICP-AES).

\begin{tabular}{lcc}
\hline \multicolumn{1}{c}{ Samples } & \multicolumn{2}{c}{$\begin{array}{c}\text { Lead concentration } \\
(\boldsymbol{\mu g} / \mathbf{L})\end{array}$} \\
& ICP-AES & 3D system \\
\hline $\begin{array}{l}\text { Industrial zone (electronic manufacturing) } \\
\text { (upstream) }\end{array}$ & $17.4 \pm 1.6$ & $15.8 \pm 2.5$ \\
$\begin{array}{l}\text { Industrial zone (electronic manufacturing) } \\
\text { (downstream) }\end{array}$ & $15.1 \pm 0.8$ & $13.8 \pm 1.5$ \\
WWTP (upstream) & $16.5 \pm 1.8$ & $18.7 \pm 2.1$ \\
WWTP (direct downstream) & $17.4 \pm 2.2$ & $16.6 \pm 0.8$ \\
River - (12km downstream) & $12.9 \pm 0.4$ & $11.6 \pm 1.4$ \\
\hline
\end{tabular}

3

4 